\title{
Pediatrics Germ Cell Tumors: A Ten Year Audit in a Cancer Center of Nepal.
}

\author{
Krishna Sagar Sharma ${ }^{1}$, S Mehta ${ }^{2}$, D Misra ${ }^{2}$, Sabita Panthi ${ }^{3}$, Jitendra Pariyar ${ }^{4}$, \\ ${ }^{1}$ Consultant and Head, Department of medical oncology, Pediatric Oncology Unit, B. P. Koirala Memorial Cancer Hospital, Bharatpur, Nepal ${ }^{1}$ \\ ${ }^{2}$ Medical officer, Department of medical oncology, Pediatric Oncology Unit, B. P. Koirala Memorial Cancer Hospital, Bharatpur, Nepal ${ }^{2}$ \\ ${ }^{3}$ Senior Nursing officer and Nursing Chief, Department of Nursing, B. P. Koirala Memorial Cancer Hospital, Bharatpur, Nepal ${ }^{3}$ \\ ${ }^{4}$ Consultant, Gynecological oncology Unit, Civil Service Hospital, Kathmandu, Nepal ${ }^{4}$
}

\begin{abstract}
Introduction: Pediatric Germ cell tumors are rare disease in pediatric and adolescent age group. Germ cell tumors are the most frequently found malignancies which are highly chemosensitive. GCTs are curable if diagnosed and treated adequately even in resources poor setting in resource constraints countries like Nepal.

Objective: To study the clinicopathological profile and treatment outcome of Pediatrics Germ cell tumors (GCTs) among children and adolescent group seeking treatment at B.P. Koirala Memorial Cancer Hospital (BPKMCH), Nepal.

Methodology: Descriptive study was done at BPKMCH Nepal. All available case records of pediatric and adolescent girls diagnosed to have GCTs from 2002 to 2011 were collected and analyzed in terms of age, clinical features, malignancy types, treatment modalities and outcome.

Results: Total 70 girls were with female gynecological malignancy. There are $46(76.66 \%)$ with ovarian malignancies. Among the ovarian cancers, 42 had malignant germ cell cancer (91.3\%) among all ovarian malignancies which are enrolled in the study. The commonest presentation was abdominal distension and pain in $70 \%$. Onset of symptoms ranged from three days to 730 days (mean 95 days). Disease stage at presentation was early stage 18 (30\%) and advanced disseminated disease 42 (70\%). In treatment modality, 8 (13.33\%) underwent fertility sparing surgery only, 21(35\%) underwent chemotherapy only and 31(51.66\%) underwent multimodality treatment. $82.5 \%$ patients who were completed recommended treatment were cured.
\end{abstract}

Conclusion: Malignant germ cell cancer is the commonest ovarian malignancies among pediatric and adolescent girls. Early presentation and prompt appropriate treatment would offer chances of cure even with preservation of fertility.

Keywords: Germ cell tumor, Gestational Trophoblastic disease.

\section{Introduction}

Germ cell tumors are rare in pediatric and adolescent girls among all malignancies. Germ cell tumors (GCTs) are the most frequently found ovarian malignancies in pediatric and adolescent age group, which are highly chemo-sensitive. GCTs are a rare and heterogeneous group of tumors that account for $3 \%$ of pediatric cancers. Generally, in children age under 15 years GCTs predominantly in female child (M: $\mathrm{F}=0.8: 1) .{ }^{1}$ The age distribution of GCTs is bimodal, in which the first peak is seen before the age of one year and the second peak starts along with puberty in adolescence. ${ }^{2,3}$ The incidence of GCTs have increased in children in western world like United states, Europe and Australia., 5, 6 The reason is not well known. GCTs are assumed to originate from the primordial germ cells in growing embryo in embryogenesis, which migrate along the midline of the body to the gonadal ridge. ${ }^{7-9}$ The GCTs in extra

Correspondence

Dr Krishna Sagar Sharma, MD, Consultant and Head, Medical Oncology, B.P. Koirala Memorial Cancer Hospital, B P Koirala Memorial Cancer Hospital, Bharatpur, Chitwan, Nepal. akrish630@gmail.com. 
gonadal site are believed to form due to failure of proper migration to gonad. ${ }^{10}$

In the pre-chemotherapy era, even localized malignant non-germinomatous ovarian GCTs were associated with survival of only $20 \% .{ }^{11}$ with the advent of platinum based regime for testicular cancer in 1977, there has been dramatically improve on survival ${ }^{12}$ and subsequently apply for all extra cranial GCTs in children. ${ }^{13}$ Although survival for those with treated with platinum based chemotherapy in early stage GCTs is more than $90 \% .{ }^{14}$ with the application of similar regime even in resource poor setting survival improved dramatically with higher cure rate. Life threatening late side effects of chemotherapy is the major challenge. Renal impairment, neurotoxocity and hearing loss are well recognized tocities. ${ }^{15}$ Recent long term follow up studies of man testicular cancer have shown two fold increase in cardiovascular disease and second malignancy in adult mainly Hodgkin's lymphoma. ${ }^{16}$ Theses side effect are not know in pediatric though the therapy are nearly identical. Therefore we need to have more conscious on treating with chemotherapy agent and need to have follow up for long time for future toxicities.
The aim and objective of this study is to find out the clinic-pathological profile of pediatric Germ cell tumors and their treatment outcome among pediatric and adolescent group ( $<19$ years) seeking treatment at B.P. Koirala Memorial Cancer Hospital (BPKMCH), Nepal from 2002 to 2011.

\section{Method}

This is the descriptive study which was carried out at B. P. Koirala Memorial Cancer Hospital, Bharatpur, Chitwan (BPKMCH) Nepal. All available case records of pediatric and adolescent girls age less than 19 years with diagnosed to have GCTs from 2002 to 2011 were collected from hospital as well as departmental records. The diagnosis of inclusion was germ cell tumors like teratomas, embryonal carcinoma, choriocarcinoma. These children with GCTs were analyzed for their initial symptoms, diagnostic criteria's and categorize and stage according to COG guideline (Table 1). We tried to extract much information as far as possible and revised staging was done on the basis of COG guideline. These malignancies were analyzed in term of age, clinical features, malignancy types, treatment modalities and outcome of these children and adolescence.

Table 1: Pediatric and adolescent GCTs, Staging and Risk Stratification

\begin{tabular}{|c|c|c|c|}
\hline \multicolumn{4}{|c|}{ Testis, ovaries and extra gonadal COG staging } \\
\hline \multicolumn{4}{|c|}{ Staging criteria } \\
\hline Stage & Testis & Extra-gonadal & Ovary \\
\hline I & $\begin{array}{l}\text { Complete resection: high } \\
\text { inguinal or high ligation scrotal } \\
\text { orchiectomy and negative nodes }\end{array}$ & $\begin{array}{l}\text { Complete resection at any } \\
\text { site with negative margin } \\
\text { or coccygectomy for } \\
\text { sacrococcygeal teratoma }\end{array}$ & $\begin{array}{l}\text { Limited to ovary (peritoneal evaluation } \\
\text { should be negative), no clinical, } \\
\text { histological or radiographic evidence of } \\
\text { disease outside ovary }\end{array}$ \\
\hline II & $\begin{array}{l}\text { Trans-scrotal biopsy, microscopic } \\
\text { disease in scrotum or cord, or } \\
\text { failure of serum tumor markers } \\
\text { to normalize }\end{array}$ & $\begin{array}{l}\text { Microscopic residual, with } \\
\text { lymph nodes negative }\end{array}$ & $\begin{array}{l}\text { Microscopic residual, peritoneal } \\
\text { evaluation negative, failure of serum } \\
\text { tumor marker to normalize }\end{array}$ \\
\hline III & $\begin{array}{l}\text { Retroperitoneal lymph node } \\
\text { involvement, but no visceral or } \\
\text { extra-abdominal involvement }\end{array}$ & $\begin{array}{l}\text { Lymph node involvement, } \\
\text { gross residual disease or } \\
\text { biopsy only }\end{array}$ & $\begin{array}{l}\text { Lymph node involvement, metastatic } \\
\text { nodule, gross residual disease or biopsy } \\
\text { only contiguous visceral involvement } \\
\text { (omentum, intestine, and bladder) } \\
\text { peritoneal evaluation positive for } \\
\text { malignancy }\end{array}$ \\
\hline IV & Distant metastases, including liver & Distant metastasis, including liver & Distant metastases, including Liver \\
\hline
\end{tabular}


We have categorizes all malignancies in low risk (early stage), intermediate risk (advanced disease) and high risk (distant metastatic disease). Early stage diseases underwent surgery and close follow up. Advanced stage disease was managed with neoadjuvent chemotherapy to down stage disease and completion surgery. High risk malignancies were treatment with neo-adjuvant chemotherapy, interval debulking surgery with fertility preservation where as high risk malignancies were treated with neo-adjuvent chemotherapy, debulking surgery if possible and supportive care along with palliative chemotherapy.

All the patients were recommended BEP Regime, Bleomycin $15 \mathrm{mg} / \mathrm{m}^{2}$ weekly, Etoposide $100 \mathrm{mg} / \mathrm{m}^{2}$ day $1-5$, three weekly and Cisplatin $20 \mathrm{mg} / \mathrm{m}^{2}$ day $1-5$ three weekly. Those patient were no afforded Bleomycin and or unable to follow up weekly, received only EP regime, Etoposide $100 \mathrm{mg} / \mathrm{m}^{2} \&$ Cisplatin $20 \mathrm{mg} / \mathrm{m}^{2}$ three weekly. Not metastasized patient with adequate surgery received four cycle of chemotherapy. If there any residual, further two cycle of chemotherapy given to patients. In advanced distanced metastasized group received total six cycle of BEP and even more cycle after evaluation of treatment response. These patients follow up record were also collected during the study.

\section{Results}

There were total 1630 children and adolescent diagnosed with cancer during study period. Total of 53 children and adolescent girls were diagnosed as germ cell tumors which was $3.25 \%$. There were $8.3 \%$ below five years, $23.3 \%$ between $6-12$ years and $68.4 \%$ patients between 13-19 years.

Germ cell tumors were mostly located at ovarian site in $42(76.66 \%)$ and gestational trophoblastic disease in 11 (18.33\%). Among the ovarian cancers, 42 had malignant germ cell cancer $91.3 \%$. Among Malignant germ cell tumors immature teratoma (28\%), yolk sac tumor (24\%), mixed GCT (24\%) remained top three ovarian malignancies. Rests were dysgerminoma (15\%)..

Table:2 Diagnosis of ovarian germ cell tumors

\begin{tabular}{|l|l|c|}
\hline \multicolumn{1}{|c|}{ Histology Type } & \multicolumn{1}{c|}{ frequency } & \% \\
\hline Immature teratoma & 13 & $28.26 \%$ \\
\hline Yolk sac tumors & 11 & $23.91 \%$ \\
\hline Mixed GCTs & 11 & $23.91 \%$ \\
\hline Dysgerminoma & 7 & $15.21 \%$ \\
\hline
\end{tabular}

Commonest presentation was abdominal pain and distension in $70 \%$ children and adolescent. Only abdominal mass and per vaginal bleeding being next common symptom with $13.33 \%$ each. Few were present with only abdominal pain and vomiting only.

Table:3 Common Presenting symptoms

\begin{tabular}{|l|l|l|}
\hline \multicolumn{1}{|c|}{ Symptoms } & \multicolumn{1}{c|}{ Frequency } & \multicolumn{1}{c|}{$\%$} \\
\hline Abdomen pain \& distention & 42 & $70 \%$ \\
\hline Abdominal mass & 8 & $13 \%$ \\
\hline P/V Bleeding & 8 & $13 \%$ \\
\hline Abdominal pain & 1 & $1.66 \%$ \\
\hline Vomiting & 1 & $1.66 \%$ \\
\hline Total & 60 & $100 \%$ \\
\hline
\end{tabular}

$55 \%$ the patients were reached to hospital within two months, $33 \%$ between two to six months and $8.3 \%$ more than six months .Time of presentation to hospital from onset of symptoms ranged from three days to 730 days (mean 95 days).

Table:4 Time of presentation after onset of symptoms

\begin{tabular}{|l|l|l|}
\hline \multicolumn{1}{|c|}{ Onset of symptoms } & frequency & Average day \\
\hline Within 2 months & 33 & 34 \\
\hline 2 to 6 months & 22 & 112 \\
\hline After 6 months & 5 & 327 \\
\hline
\end{tabular}

Disease stage at presentation was early stage 18 (30\%) and advanced disseminated disease 42 (70\%). In treatment modality, eight (13.33\%) underwent fertility sparing surgery only, 21(35\%) underwent chemotherapy only and $31(51.66 \%)$ underwent multimodality treatment. Most of the patients received BEP regime. Patient not affordable for bleomycin and unable to follow up weekly received EP Regime. Over all $66.66 \%$ of patients completed recommended course of treatment among then $82.5 \%$ were attended cure

\section{Discussion}

The incidence rate for GCTs in children and adolescence in developed countries was similarly reported from the European and American countries. ${ }^{17}$ In contrast to the GCTs in adulthood, which are mostly gonadal and encountered in male subjects, ${ }^{21}$ the tumors in childhood were mostly extragonadal and in girls. The ratio of extragonadal/gonadal tumors (58\% extragonadal) was equal to the other published ratios. ${ }^{18}$ Median age at 
diagnosis varied according to tumor location, type, and gender, indicating the heterogeneity of the GCTs. The large difference seen in the median age at diagnosis between boys and girls for the gonadal GCTs most likely reflects biological differences. In boys, the germ cells undergo mitotic proliferation before and after birth, where as in unborn girls, the cells are subjected to meiotic arrest and are reactivated only in puberty. Accordingly, the incidence rate of testicular tumors peaked in boys before the age of 2 years and experienced a new rise at the onset of puberty, whereas in girls, the incidence rate of ovarian GCTs started to increase after the age of five years and continued toward puberty and was the highest for 10 to 14 year olds. ${ }^{18,19,20}$ For GCTs, the diagnostics have been improved by the introduction of certain biochemical methods and computer tomography in the mid 1980s, which may have led to increased incidence rates in the 1980s. ${ }^{21}$

During the past 35 years, survival rates for children gyenecological malignancies especially with extracranial malignant germ cell tumors (GCTs) have increased significantly. Success has been achieved primarily through the application of platinum-based chemotherapy regimens; however, clinical challenges in GCTs remain. ${ }^{22}$ Excellent outcomes are not distributed uniformly across the heterogeneous distribution of age, histologic features and primary tumor site. Despite overall good outcomes, the likelihood of a cure for certain sites and histologic conditions is less than 50\%. In addition, there are considerable long-term treatment-related effects for survivors. Even modest cisplatin dosing can cause significant long-term morbidities. A particular challenge in designing new therapies for GCT is that a variety of specialists use different risk stratifications, staging systems, and treatment approaches for three distinct age groups (childhood, adolescence, and young adulthood). Traditionally, pediatric cancer patients younger than 15 years have been treated by pediatric oncologists in collaboration with their surgical specialty colleagues. ${ }^{22}$ Adolescents and young adults with GCTs often are treated accordingly. The therapeutic dilemma for all is how to best define disease risk so that therapy and toxicity can be appropriately reduced for some patients and intensified for others. Due to the lack of adequate diagnosis, individualize therapy and lack of other advanced treatment option we are not able to limit the chemotherapy dose. ${ }^{22}$ Timely and adequately treated GCTs may increase the cure rate even is developing countries. Regular long term follow up for side effects and long term survivorship follow up programme should be started for it monitoring. Furthermore, multicentric study based on common protocol is necessary to enrich our knowledge in our setting for cutting edges in the management of GCTs. There are other GCTs beyond reproductive organ line in central nerves system, spine and thorax. These tumors are also need especial management protocol for better outcome.

\section{Conclusion}

Malignant germ cell cancer is the commonest gynecologic malignancy among pediatric and adolescent girls. We achieved $82.5 \%$ cure rate who were completed the recommended course of treatment. In our children adolescent peak is higher with almost uniform in other age group. In country where childhood marriage is still prevalent, GTT is also more common among adolescent girls. Early presentation and prompt appropriate treatment would offer chances of cure even with preservation of fertility. Still significant number of patients present at advanced stage (66\%) and almost one third of them abandon treatment. Is shows the serious concern about lack of awareness and discontinue treatment where cure was possible. BEP is the mainstay of treatment and different measure has to taken to minimized chemotherapy dose to avoid toxicity and long term side effects. Only $24 \%$ of patient after cure were on follow up. Long term follow up is required to monitor post treatment status and various issues like second malignancies, hormonal disorders, fertility, physical as well as psychological issues.

\section{Acknowledgments}

I would like to acknowledge to all the doctors, nurses, administrative staff who are directly and indirectly involved in this study. I also like to acknowledge the all the children and adolescent who underwent treatment in our centre.

\section{References}

1. Kaatsch P. Epidemiology of childhood cancer. Cancer Treat Rev. 2010;36 (4): 277-285

2. Schneider DT, Calaminus G, Koch S, et al. Epidemiologic analysis of 1,442 children and adolescents registered in the German germ cell tumor protocols. Pediatr Blood Cancer. 2004; 42 (2): 169-175 
3. Poynter JN, Amatruda JF, Ross JA. Trends in incidence and survival of pediatric and adolescent patients with germ cell tumors in the United States, 1975 to 2006. Cancer. 2010; 116 (20): 4882-4891

4. Howlader N, Noone AM, Krapcho M, et al, eds. SEER Cancer Statistics Review, 1975-2011, Bethesda, MD: National Cancer Institute. Available at: http://seer. cancer.gov/csr/1975_2011/. Accessed April 15, 2014

5. Kaatsch P, Steliarova-Foucher E, Crocetti E, Magnani C, Spix C, Zambon P. Time trends of cancer incidence in European children (1978-1997): report from the Automated Childhood Cancer Information System project. Eur J Cancer. 2006;42 (13):1961-1971

6. Baade PD, Youlden DR, Valery PC, et al. Trends in incidence of childhood cancer in Australia, 19832006. Br J Cancer.2010; 102 (3):620-626

7. Teilum G. Classification of endodermal sinus tumour (mesoblatoma vitellinum) and so-called "embryonal carcinoma" of the ovary. Acta Pathol Microbiol Scand. 1965; 64(4):407-429.

8. Rescorla FJ. Pediatric germ cell tumors. Semin Surg Oncol. 1999; 16(2):144-158.

9. Schneider DT, Schuster AE, Fritsch MK, et al. Multipoint imprinting analysis indicates a common precursor cell for gonadal and nongonadal pediatric germ cell tumors. Cancer Res. 2001; 61(19): 72687276.

10. Oosterhuis JW, Stoop H, Honecker F, Looijenga LH. Why human extragonadal germ cell tumours occur in the midlineof the body: old concepts, new perspectives. Int J Androl. 2007; 30 (4): 256-263; discussion 263-264.

11. Kurman RJ, Norris HJ: Endodermal sinus tumor of the ovary: A clinical and pathologic analysis of 71 cases. Cancer 38:2404-2419, 1976.

12. Einhorn LH, Donohue JP: Improved chemotherapy in disseminated testicular cancer. J Urol 117:65-69, 1977.

13. Cushing B, Giller R, Cullen JW, et al: Randomized comparison of combination chemotherapy with etoposide, bleomycin and either high-dose or standard-dose cisplatin in children and adolescents with high-risk malignant germ cell tumors: A pediatric intergroup study-Pediatric Oncology
Group 9049 and Children's Cancer Group 8882. J Clin Oncol 22:2691-2700, 2004.

14. Rogers PC, Olson TA, Cullen JW, et al: Treatment of children and adolescents with stage II testicular and stages I and II ovarian malignant germ cell tumors: A Pediatric Intergroup Study-Pediatric Oncology Group 9048 and Children's Cancer Group 8891. J Clin Oncol 22:3563-3569, 2004.

15. Hale GA, Marina NM, Jones-Wallace D, et al: Late effects of treatment for germ cell tumors during childhood and adolescence. J Pediatr Hematol Oncol 21:115-122, 1999.

16. Travis LB, Beard C, Allan JM, et al: Testicular cancer survivorship: Research strategies and recommendations. J Natl Cancer Inst 102:11141130, 2010.

17. Li J, Thompson TD, Miller JW, Pollack LA, Stewart SL. Cancer incidence among children and adolescents in the United States, 2001-2003. Pediatrics, 2008; 121 (6). Available at: www.pediatrics.org/ cgi/content/ full/121/6/e1470.

18. Ries LAG, Smith MA, Gurney JG, et al, eds. Cancer Incidence and Survival Among Children and Adolescents: United States SEER Program 19751995. Bethesda, MD:National Cancer Institute, SEER.

19. Castleberry R, Cushing B, Perlman E, et al. Germ cell tumors. In: Principles and Practice of Pediatric Oncology. Philadelphia, PA: Lippincott-Raven; 1997:921-945.

20. Pinkerton CR. Malignant germ cell tumours in childhood. Eur J Cancer. 1997; 33 (6):895-901, discussion 901-902.

21. Kroll ME, Carpenter LM, Murphy MF, Stiller CA. Effects of changes in diagnosis and registration on time trends in recorded childhood cancer incidence in Great Britain. Br J Cancer. 2012; 107(7):11591162.

22. Thomas A. Olson, Matthew J. Murray, Carlos Rodriguez-Galindo, James C. Nicholson, Deborah F. Billmire, at al .Pediatric and Adolescent Extracranial Germ Cell Tumors: The Road to Collaboration. J Clin Oncol J Clin Oncol 33:3018-3028, 2015. 